\title{
DEVELOPMENTAL DIFFERENCES IN CYTOSOLIC CALCIUM ACCUMULATION ASSOCIATED WITH SURGICALLY INDUCED GLOBAL ISCHEMIA: OPTIMIZATION OF CARDIOPLEGIC PROTECTION AND MECHANISM OF ACTION
}

Takuro Tsukube, MD, PhD

James D. McCully, PhD

Micheline Federman, PhD

Irvin B. Krukenkamp, MD

Sidney Levitsky, MD
Objective: The effect of cardioplegic solutions with high concentrations of potassium or magnesium (or both) on cytosolic calcium accumulation was investigated with fura- 2 in isolated perfused mature $(n=24)$ and aged $(n=$ 24) rabbit hearts. Methods: We compared cytosolic calcium accumulation before ischemia (control), during $\mathbf{3 0}$ minutes of ischemia and 30 minutes of reperfusion under global ischemia, or after treatment with potassium (20 mmol/L), magnesium $(20 \mathrm{mmol} / \mathrm{L})$, or both. Results: Cytosolic calcium accumulation was increased during global ischemia in the mature heart (from $178.7 \pm 24.2$ in the control group to $393.6 \pm 25.5 \mathrm{nmol} / \mathrm{L} ; p<0.005$ ) and in the aged heart (from 187.4 \pm 18.7 in the control group to $501.0 \pm$ $46.1 \mathrm{nmol} / \mathrm{L} ; p<0.005)$. Potassium reduced cytosolic calcium accumulation during ischemia in both the mature and aged hearts $(300.9 \pm 23.2$ and $365.2 \pm 27.7 \mathrm{nmol} / \mathrm{L}$, respectively; $p<0.05$ vs global ischemia). Magnesium and potassium/magnesium completely controlled cytosolic calcium accumulation in the mature heart $(198.7 \pm 27.5 \mathrm{nmol} / \mathrm{L} ; p<0.01$ vs global ischemia and $p<0.05 \mathrm{vs}$ potassium: $182.3 \pm 22.7 \mathrm{nmol} / \mathrm{L} ; p<0.05 \mathrm{vs}$ global ischemia and potassium, respectively). Magnesium and potassium/magnesium attenuated cytosolic calcium accumulation in the aged heart $(261.3 \pm$ $26.7,262.3 \pm 25.2 \mathrm{nmol} / \mathrm{L}$, respectively; $p<0.01 \mathrm{vs}$ global ischemia). These changes in cytosolic calcium accumulation correlated with improved postischemic ventricular function. To investigate the mechanism(s) of magnesium-supplemented cardioplegic inhibition of cytosolic calcium accumulation, we performed parallel studies $(n=43)$ using nifedipine, ryanodine, and dimethylthiourea. Nifedipine with or without ryanodine reduced cytosolic calcium accumulation. Dimethylthiourea did not alter cytosolic calcium accumulation during global ischemia. Our results suggest that cytosolic calcium accumulation during global ischemia was mainly increased via the sarcolemmal 1-type calcium channel and the sarcoplasmic reticulum calcium-release channel. The modulating action of potassium/ magnesium cardioplegia on cytosolic calcium accumulation during ischemia would appear to act through the inhibition of the myocardial 1-type calcium channel and the sarcoplasmic reticulum calcium-release channel. Conclusion: Senescent cardiac dysfunction correlates with increased ischemia-induced cytosolic calcium accumulation. Magnesium-supplemented potassium cardioplegia ameliorates this age-related phenomenon at normothermia and may have important implications in myocardial protection in the elderly population. (J Thorac Cardiovasc Surg 1996;112:175-84)
From the Division of Cardiothoracic Surgery and the Department of Pathology, New England Deaconess Hospital and Harvard Medical School, Boston, Mass.

Supported by the National Institutes of Health (HL 29077).

Received for publication March 27, 1995; accepted for publication July 19, 1995.
Address for reprints: Sidney Levitsky, MD, Division of Cardiothoracic Surgery, New England Deaconess Hospital, 110 Francis St., Suite 2C, Boston, MA 02215.

Copyright $(\mathcal{O} 1996$ by Mosby-Year Book, Inc.

$0022-5223 / 96 \$ 5.00+0 \quad \mathbf{1 2 / 1 / 6 8 3 9 5}$ 
$I^{n}$ $\mathrm{n}$ the aged myocardium calcium homeostasis is altered, so that the aged heart is more susceptible to calcium overload. ${ }^{1}$ In previous reports, we $\mathrm{e}^{2}$ have shown that surgically induced global ischemia is associated with alteration in cytosolic calcium $\left[\mathrm{Ca}^{2+}\right]_{\mathrm{i}}$ accumulation and that myocardial functional recovery during reperfusion is correlated with this phenomenon. $\mathrm{We}^{2}$ have also demonstrated that the aged myocardium is more susceptible to $\left[\mathrm{Ca}^{2+}\right]_{i}$ accumulation during ischemia and that functional recovery during reperfusion is poorer than that of the mature myocardium. The age-related differences in functional recovery were correlated with lower $\left[\mathrm{Ca}^{2+}\right]_{\mathrm{i}}$ accumulation during ischemia. These data have led us to investigate techniques that would allow for the modulation of $\left[\mathrm{Ca}^{2+}\right]_{i}$ accumulation during ischemia and enhance myocardial functional recovery after ischemia and reperfusion in the aged heart.

Cardioplegia has been shown to partially ameliorate $\left[\mathrm{Ca}^{2+}\right]_{\mathrm{i}}$ accumulation from surgically induced myocardial ischemia during cardiac operations. ${ }^{3}$ The use of hypothermic potassium cardioplegic solution in adult cardiac operations increases the available global ischemic time and has been correlated with improved postischemic myocardial functional recovery and reduced postoperative mortality. ${ }^{4}$ Potassium-induced arrest maintains the heart in a depolarized state. ${ }^{5}$ However, depolarization also leads to the alteration of the ion flux across the sarcolemmal membrane and is associated with both increased $\left[\mathrm{Ca}^{2+}\right]_{\mathrm{i}}$ accumulation and the significant depletion of cellular adenosine triphosphate reserves. ${ }^{5}$

Alternatives to potassium cardioplegia have been suggested to allow for enhanced functional recovery of the myocardium after ischemia and reperfusion. Hearse and associates ${ }^{6,7}$ reported that magnesium, when added to potassium cardioplegic solutions, was beneficial to myocardial coronary flow and aided in the reduction of myocardial enzymatic leakage after ischemia and reperfusion. The mechanism of magnesium-supplemented potassium cardioplegia in providing for enhanced functional recovery remains to be elucidated.

In this report we have used the fluorescent calcium indicator fura-2 to quantitatively measure $\left[\mathrm{Ca}^{2+}\right]_{i}$ accumulation during normothermic global ischemia and reperfusion. The use of potassium or magnesium-supplemented potassium cardioplegia in modulating $\left[\mathrm{Ca}^{2+}\right]_{\mathrm{i}}$ accumulation during $30 \mathrm{~min}$ utes of global ischemia and 30 minutes of reperfu- sion was investigated, and the effect of cardioplegia on myocardial functional recovery in both the mature and aged rabbit heart was determined. We have also investigated the mechanism of action of potassium or potassium/magnesium cardioplegia on $\left[\mathrm{Ca}^{2+}\right]_{\mathrm{i}}$ accumulation during ischemia.

\section{Materials and methods}

Animals. New Zealand White rabbits $(n=91)$ were obtained from Millbrook Farm, Amherst, Massachusetts. Rabbits 15 to 20 weeks of age were classified as mature, according to sexual maturity. Rabbits older than 130 weeks ( 2.5 years) with a maximal life span of 3 years were classified as aged. All animals were housed individually and provided with laboratory chow and water ab libitum. All experiments were approved by the New England Deaconess Hospital Animal Care and Use Committee and conformed to the U.S. National Institutes of Health guidelines regulating the care and use of laboratory animals.

Langendorff perfusion. The rabbits (15 to 20 weeks, mature, $n=24$; more than 130 weeks, aged, $n=24$ ) were anesthetized with sodium pentobarbital (Nembutal, 100 $\mathrm{mg} / \mathrm{kg}$ intravenously), and heparin (200 units $/ \mathrm{kg}$ intravenously) was administered. The heart was then excised and placed in a $4^{\circ} \mathrm{C}$ bath of Krebs-Ringer solution, where spontaneous beating ceased within a few seconds. Langendorff perfusion was performed as previously described. ${ }^{8,9}$ The heart was perfused with modified Krebs-Ringer solution at a constant pressure of $75 \mathrm{~cm} \mathrm{H}_{2} \mathrm{O}$ at $37^{\circ} \mathrm{C}$. The heart was perfused for 30 minutes to stabilize the hemodynamics. Left ventricular pressure was recorded, and an electrocardiogram was obtained with electrodes placed on the epicardial surface of the right ventricle. The heart was placed into the water-jacketed chamber, and myocardial temperature was maintained at $37^{\circ} \mathrm{C}$.

Measurement of $\left[\mathrm{Ca}^{2+}\right]_{i}$ accumulation and hemody namics. The fluorescent calcium indicator fura- 2 was used to measure quantitatively $\left[\mathrm{Ca}^{2+}\right]_{i}$ accumulation. ${ }^{8}$

Calibration of $\left[\mathrm{Ca}^{2+}\right]_{\mathrm{i}}$ concentration. The fura-2 fluorescence ratio was calculated as previously described. ${ }^{2,9}$

Cardioplegia protocols. Four cardioplegia protocols for each age were investigated during 30 minutes of normothermic ischemia, achieved by clamping the ascending aorta, followed by 30 minutes of reperfusion. The perfusion system incorporates two circuits: one supplies Krebs-Ringer solution and the other is used for infusion of cardioplegic solution. After equilibrium the ascending aorta was crossclamped and the flow of Krebs-Ringer solution was ceased. Cardioplegic solution was then perfused via the second circuit for 5 minutes and that circuit was crossclamped. The four cardioplegia protocols investigated were as follows: (1) hearts subjected to normothermic ischemia and reperfusion without cardioplegia (global protocol); (2) hearts subjected to normothermic ischemia and reperfusion after potassium arrest (20 $\mathrm{mmol} / \mathrm{L}$ concentration of potassium chloride in modified Krebs-Ringer solution; K protocol); (3) hearts subjected to normothermic ischemia and reperfusion after magnesium infusion $(20 \mathrm{mmol} / \mathrm{L}$ concentration of magnesium in 
modified Krebs-Ringer solution; $\mathrm{Mg}$ protocol); and (4) hearts subjected to normothermic ischemia and reperfusion after magnesium-supplemented potassium arrest (20 $\mathrm{mmol} / \mathrm{L}$ concentrations of potassium chloride and magnesium in modified Krebs-Ringer solution, $\mathrm{K} / \mathrm{Mg}$ protocol). All protocols were performed with six mature and six aged hearts. Cardioplegic solutions were perfused at a constant pressure of $75 \mathrm{~cm} \mathrm{H}_{2} \mathrm{O}$ at $37^{\circ} \mathrm{C}$ for 5 minutes before the start of ischemia. Fluorescence signals were measured every 5 minutes during ischemia and reperfusion with left ventricular peak developed pressure (LVPDP) and enddiastolic pressure (LVEDP).

Channel blockers. To investigate the mechanism(s) of magnesium-supplemented cardioplegic inhibition of $\left[\mathrm{Ca}^{2+}\right]_{i}$ accumulation during 30 minutes of normothermic global ischemia, we performed parallel studies $(n=43)$ using nifedipine, ryanodine, and dimethylthiourea. The calcium channel blockers were added before cardioplegia to ensure their distribution and effectiveness. Seven cardioplegia protocols were investigated. Hearts were subjected to 30 minutes of normothermic global ischemia after treatment with (1) nifedipine (cardiac sarcolemmal 1-type calcium channel blocker, $n=6$ ), (2) ryanodine (sarcoplasmic reticulum calcium channel blocker, $n=6$ ), (3) nifedipine and ryanodine $(n=6)$, (4) dimethylthiourea (sarcolemmal sodium/calcium exchanger blocker, ${ }^{10} n$ $=7)$, (5) potassium cardioplegia with nifedipine $(n=6)$, (6) potassium cardioplegia with ryanodine $(n=6)$, and (7) potassium cardioplegia with nifedipine and ryanodine $(n=6)$.

Nifedipine-treated hearts were perfused with a $1 \times$ $10^{-7} \mathrm{~mol} / \mathrm{L}$ concentration of nifedipine (Sigma Chemical Co., St. Louis, Mo.) in Krebs-Ringer solution for 10 minutes before ischemia. Ryanodine-treated hearts were perfused with a $1 \times 10^{-6} \mathrm{~mol} / \mathrm{L}$ concentration of ryanodine (Calbiochem Co., La Jolla, Calif.) in Krebs-Ringer solution for 20 minutes before ischemia. Nifedipine/ryanodine-treated hearts were perfused with a $1-10^{-7}$ $\mathrm{mmol} / \mathrm{L}$ concentration of nifedipine and a $1 \times 10^{-6} \mathrm{~mol} / \mathrm{L}$ concentration of ryanodine in Krebs-Ringer solution for 20 minutes before ischemia. Dimethylthiourea-treated hearts were perfused with a $25 \mathrm{mmol} / \mathrm{L}$ concentration of 1,3-dimethyl-2-thiourea (Aldrich Chemical Co., Inc., Milwaukee, Wis.) in Krebs-Ringer solution for 20 minutes before ischemia. Potassium arrest was induced by perfusing with Krebs-Ringer solution containing a $20 \mathrm{mmol} / \mathrm{L}$ concentration of potassium for 3 minutes after each chemical treatment was ceased. Calcium channel blockers and potassium cardioplegic solution were perfused from separate perfusion reservoirs to prevent cross contamination, at a constant pressure of $75 \mathrm{~cm} \mathrm{H}_{2} \mathrm{O}$ at $37^{\circ} \mathrm{C}$.

Comparison of wet and dry weights. Frozen samples from all experimental groups were weighed (wet weight) and dried at $80^{\circ} \mathrm{C}$ for 24 hours for reweighing (dry weight) and determination of wet/dry weight ratios. ${ }^{9}$

Transmission electron microscopy. Mature and aged heart samples were obtained after 30 minutes of normothermic global ischemia. They were routinely fixed for electron microscopy with Karnofsky's fixative and embedded in epoxy resin. Thin sections were stained with uranyl acetate and lead citrate and examined with a Hitachi 600 electron microscope (Hitachi Instruments,
Inc., Danbury, Conn.). ${ }^{9}$ All samples were examined and graded by a single experienced observer, blinded to the protocol and the results.

Statistical analysis. Statistical analysis was performed with the use of the Stat View II software package (Abacus Concepts, Inc., Calif.). The mean \pm the standard error of the mean for all data was calculated for all variables and significance was determined within and between groups by means of a one-way analysis of variance followed by Tukey's range test. Statistical significance was claimed only at $p<0.05$.

\section{Results}

$\left[\mathrm{Ca}^{2+}\right]_{i}$ accumulation during ischemia in the mature heart. In mature hearts subjected to ischemia and reperfusion without cardioplegia (global protocol, $n=6$ ), the level of $\left[\mathrm{Ca}^{2+}\right]_{i}$ was significantly increased above preischemic levels 5 minutes after the onset of ischemia $(p<0.005$ vs preischemic value) and steadily increased to the maximal level by 30 minutes of ischemia ( $p<0.005$ vs preischemic value) (Fig. 1, $A$, Table I). After the onset of reperfusion, the level of $\left[\mathrm{Ca}^{2+}\right]_{\mathrm{i}}$ began to decrease within 5 minutes from $393.6 \pm 25.5 \mathrm{nmol} / \mathrm{L}$ to $275.0 \pm 27.4 \mathrm{nmol} / \mathrm{L}$ (not significant as compared with the preischemic value). After 30 minutes of reperfusion, the level of $\left[\mathrm{Ca}^{2+}\right]_{\mathrm{i}}$ completely returned to preischemic levels $(192.3 \pm 26.7 \mathrm{nmol} / \mathrm{L})$.

Effect of cardioplegia on $\left[\mathrm{Ca}^{2+}\right]_{i}$ in the mature heart. The effect of potassium, magnesium, and magnesium-supplemented potassium cardioplegia on $\left[\mathrm{Ca}^{2+}\right]_{\mathrm{i}}$ accumulation during ischemia and reperfusion is shown in Fig. 1, $A$ for the mature rabbit heart. The use of potassium cardioplegia before global ischemia ( $\mathrm{K}$ protocol) significantly reduced $\left[\mathrm{Ca}^{2+}\right]_{i}$ as compared with results obtained with the global protocol $(p<0.001)$. Potassium cardioplegia (K protocol) reduced $\left[\mathrm{Ca}^{2+}\right]_{\mathrm{i}}$ accumulation after 30 minutes of ischemia to approximately $75 \%$ of that obtained with the global protocol $(p<0.05$, Table I). Both magnesium (Mg protocol) and magnesiumsupplemented potassium cardioplegia (K/Mg protocol) completely inhibited $\left[\mathrm{Ca}^{2+}\right]_{i}$ accumulation after 30 minutes of ischemia (Table I). No significant difference in $\left[\mathrm{Ca}^{2+}\right]_{i}$ accumulation between the $\mathrm{Mg}$ and $\mathrm{K} / \mathrm{Mg}$ protocols was found (Table I). $\left[\mathrm{Ca}^{2+}\right]_{\mathrm{i}}$ accumulation during ischemia in the aged heart.

Quantitative measurement with fura-2 indicated that preischemic ( 0 minute) $\left[\mathrm{Ca}^{2+}\right]_{i}$ was not significantly different between mature and aged hearts (range $179.3 \pm 8.2 \mathrm{nmol} / \mathrm{L}$ to $164.4 \pm 5.1 \mathrm{nmol} / \mathrm{L}$ ) in any of the groups investigated. These results indicate that the initial control $\left[\mathrm{Ca}^{2+}\right]_{i}$ did not influence 


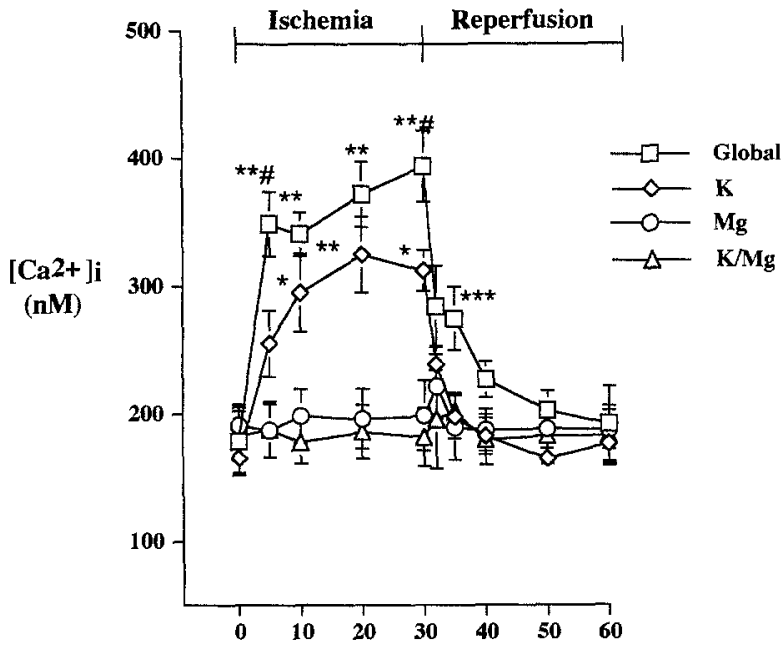

A

Time (min)

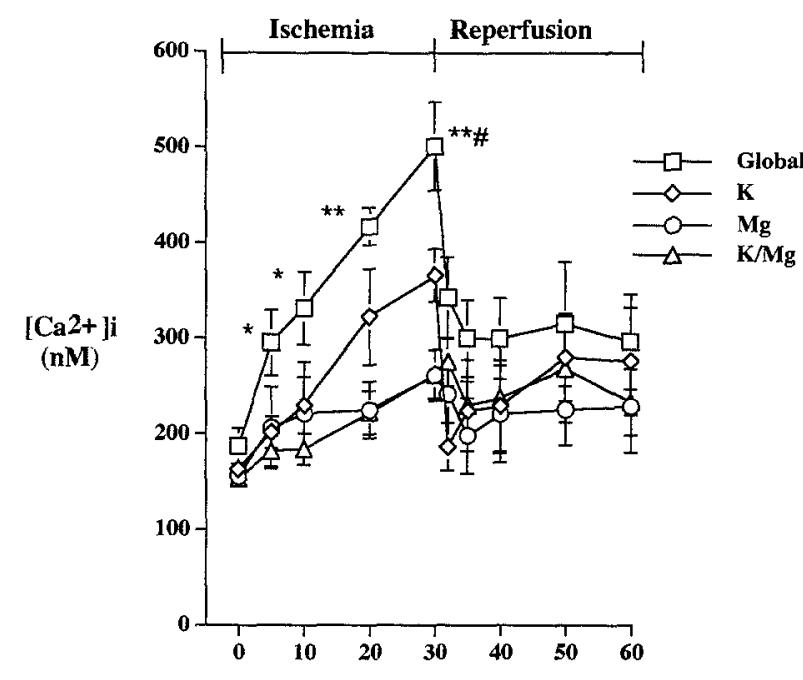

B

Time (min)

Fig. 1. $\left[\mathrm{Ca}^{2+}\right]_{\mathrm{i}}$ accumulation during 30 minutes of ischemia followed by 30 minutes of reperfusion and the effect of cardioplegia in mature (A) and in aged (B) hearts. Global, Hearts subjected normothermic global ischemia without cardioplegic protection; $K$, hearts subjected normothermic global ischemia with 20 $\mathrm{mmol} / \mathrm{L} \mathrm{KCl}$ cardioplegia; $M g$, hearts subjected normothermic global ischemia with $20 \mathrm{mmol} / \mathrm{L} \mathrm{MgSO}$ cardioplegia; $K / \mathrm{Mg}$, hearts subjected normothermic global ischemia with both $\mathrm{KCl}$ and $\mathrm{MgSO}_{4}$ cardioplegia. Control values, after 30 minutes' equilibrium, are shown at time $=0$ minutes; normothermic global ischemia, 0 to 30 minutes; reperfusion, 30 to 60 minutes. Results shown are mean \pm standard deviation for $n=6$ for each group. ${ }^{*} p<0.05$ versus $\mathrm{Mg}$ and $\mathrm{K} / \mathrm{Mg} ;{ }^{* *} p<0.01$ verus $\mathrm{Mg}$ and $\mathrm{K} / \mathrm{Mg} ; \# p<0.05$ versus $\mathrm{K} ;{ }^{* * *} p<0.05$ versus $\mathrm{K}$ and $\mathrm{Mg}$.

Table I. $\left[\mathrm{Ca}^{2+}\right]_{i}$ accumulation after 30 minutes of ischemia and the effect of cardioplegia in both mature and aged hearts

\begin{tabular}{llccc}
\hline & Global & $K$ & $M g$ & $K / M g$ \\
\hline Mature & $393.6 \pm 25.5$ & $300.9 \pm 23.2^{*}$ & $198.7 \pm 27.5 \dagger \dagger$ & $182.3 \pm 22.7 \dagger \S$ \\
Aged & $501.0 \pm 46.1 \#$ & $365.2 \pm 27.7^{*}$ & $261.3 \pm 26.7 \dagger$ & $262.3 \pm 25.2 \dagger \|$ \\
\hline
\end{tabular}

$\left[\mathrm{Ca}^{2+}\right]_{\mathrm{i}}$ is expressed as nanomoles per liter. All results are shown as mean \pm standard deviation for $n=6$ for cach group. Global: Hearts subjected to normothermic global ischemia without cardioplegic protection; $K$, hearts subjected to normothermic global ischemia with $20 \mathrm{mmol} / \mathrm{L} \mathrm{KCl}$ cardioplegia; $M g$, hearts subjected to normothermic global ischemia with $20 \mathrm{mmol} / \mathrm{L} \mathrm{MgSO}$ cardioplegia; $\mathrm{K} / \mathrm{Mg}$, hearts subjected to normothermic global ischemia with both $\mathrm{KCl}$ and $\mathrm{MgSO}_{4}$ cardioplegia. Control values were obtained after 30 minutes of equilibrium.

${ }^{*} p<0.05$ versus global.

$\uparrow p<0.01$ versus global.

末p $<0.05$ versus $\mathrm{K}$.

$\$ p<0.01$ versus $\mathrm{K}$.

$\| p<0.05$ versus mature.

the effects of the cardioplegia protocols. In aged hearts subjected to the global protocol, the level of $\left[\mathrm{Ca}^{2+}\right]_{\mathrm{i}}$ was increased above preischemic levels 5 minutes after the onset of ischemia (295.2 \pm 34.0 $\mathrm{nmol} / \mathrm{L}: p<0.05$ vs preischemic value), and after 30 minutes of ischemia $\left[\mathrm{Ca}^{2+}\right]_{\mathrm{i}}$ was increased to the maximal level ( $p<0.05$ vs preischemic value) (Fig. $1, B$, Table I). The level of $\left[\mathrm{Ca}^{2+}\right]_{i}$ was decreased by 5 minutes of reperfusion to $299.8 \pm 39.7 \mathrm{nmol} / \mathrm{L}$ ( $p<0.05$ vs 30 minutes of ischemia), and after 30 minutes of reperfusion the level of $\left[\mathrm{Ca}^{2+}\right]_{i}$ was
$296.3 \pm 49.3 \mathrm{nmol} / \mathrm{L}$ (not significantly different from control).

Effect of cardioplegia on $\left[\mathrm{Ca}^{2+}\right]_{i}$ in the aged heart. The use of potassium cardioplegia before global ischemia ( $\mathrm{K}$ protocol) significantly reduced $\left[\mathrm{Ca}^{2+}\right]_{\mathrm{i}}$ during both ischemia and reperfusion in aged hearts as compared with results with the global protocol $(p<0.0005)$. The $\mathrm{K}$ protocol reduced $\left[\mathrm{Ca}^{2+}\right]_{\mathrm{i}}$ accumulation during ischemia to approximately $75 \%$ of that observed with the global protocol after 30 minutes of ischemia in the aged heart 


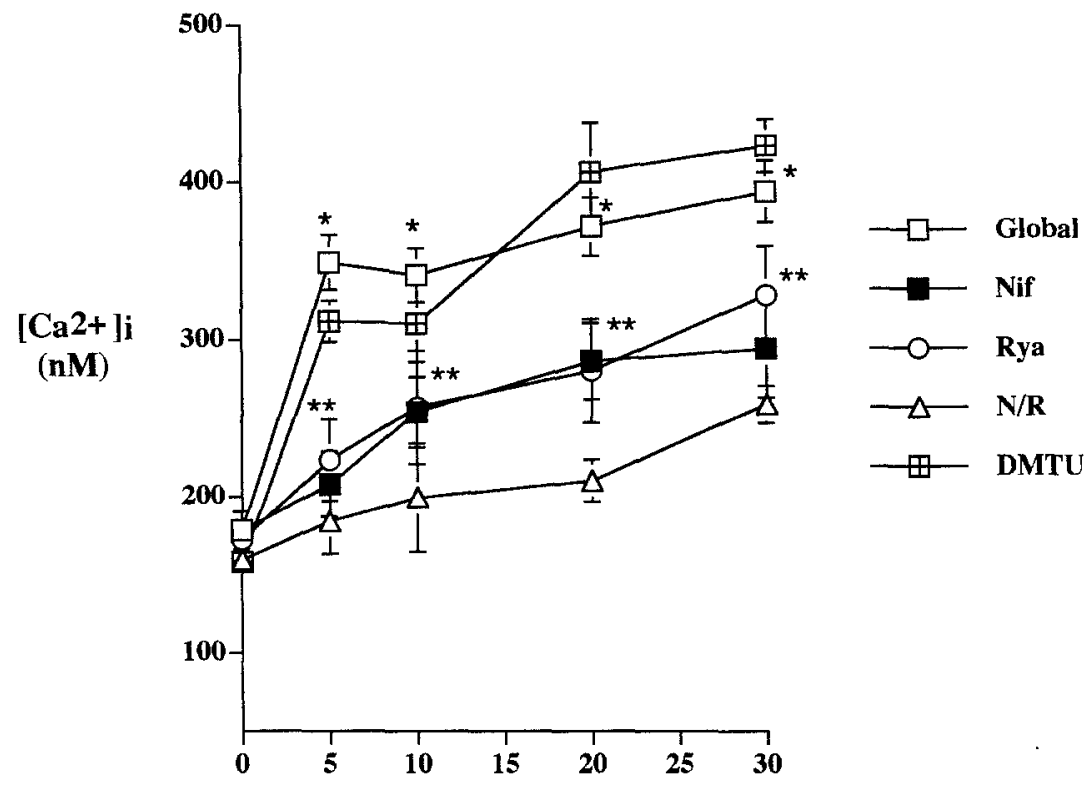

Time (min)

Fig. 2. The effect of nifedipine (Nif), ryanodine (Rya), nifedipine and ryanodine (N/R), and dimethylthiourea $(D M T U)$ on cytosolic calcium accumulation during 30 minutes of normothermic global ischemia. Global, Hearts subjected normothermic global ischemia without cardioplegic protection. Control values, after 30 minutes of equilibrium, are shown at time $=0$ minutes. Results shown are mean \pm standard deviation for $n=6$ for Nif, Rya, and N/R and $n=7$ for DMTU. Differences between groups were determined by two-factor analysis of variance and the Tukey-Kramer test. Results indicate significant differences between global and Nif, global and Rya, and global and N/R ( ${ }^{*} p<0.05$ ). Significant differences were also observed between Nif and N/R and between Rya and N/R (**p<0.05). There was no significant difference between global and DMTU.

(Fig. 2, $A$, Table I). Both the $\mathrm{Mg}$ protocol and the $\mathrm{K} / \mathrm{Mg}$ protocol significantly reduced $\left[\mathrm{Ca}^{2+}\right]_{\mathrm{i}}$ during both ischemia and reperfusion as compared with the global protocol ( $p<0.0005$ for each). No significant difference in $\left[\mathrm{Ca}^{2+}\right]_{\mathrm{i}}$ accumulation at 30 minutes of global ischemia with the use of either magnesium (Mg protocol) or magnesium-supplemented potassium cardioplegia (K/Mg protocol) was found in the aged heart.

Effect of age differences in $\left[\mathrm{Ca}^{2+}\right]_{i}$ accumulation. A significant difference in $\left[\mathrm{Ca}^{2+}\right]_{i}$ accumulation during both ischemia and reperfusion was observed between mature and aged hearts $(p<0.001)$. After 30 minutes of ischemia without cardioplegia (global protocol), $\left[\mathrm{Ca}^{2+}\right]_{\mathrm{i}}$ accumulation in the aged heart was approximately $30 \%$ above that observed in the mature heart $(p<0.05$, Table I). The effects of cardioplegia on accumulation were also significantly different between mature and aged hearts, with greater $\left[\mathrm{Ca}^{2+}\right]_{i}$ accumulation being found during global ischemia in the aged as compared with the mature heart (Table I; K protocol, $p=0.05 ; \mathrm{Mg}$ protocol, $p<0.005 ; \mathrm{K} / \mathrm{Mg}$ protocol, $p<0.005$ ).

LVEDP. Functional recovery of LVEDP after 30 minutes of reperfusion, expressed as a percentage of control, in mature and aged hearts is shown in Table II. LVEDP was significantly increased during the global protocol in both the mature and aged hearts, but the increase was significantly greater in the aged than in the mature hearts (Table II). LVEDP was significantly reduced in both mature and aged hearts by magnesium or magnesium-supplemented potassium cardioplegia ( $\mathrm{Mg}$ and $\mathrm{K} / \mathrm{Mg}$ protocols) $(p<$ 0.05 vs global protocol, Table II). Comparison between the $\mathrm{Mg}$ protocol and the $\mathrm{K} / \mathrm{Mg}$ protocol indicated no significant difference in the LVEDP reduction in mature hearts; however, in aged hearts the $\mathrm{K} / \mathrm{Mg}$ protocol was found to be significantly better than the $\mathrm{Mg}$ protocol in reducing LVEDP $(p<0.05)$.

LVPDP. The effect of $\mathrm{K}, \mathrm{Mg}$, and $\mathrm{K} / \mathrm{Mg}$ protocols on LVPDP, expressed as a percentage of control 
Table II. LVEDP and LVPDP after 30 minutes of reperfusion and the effect of cardioplegia in both mature and aged hearts

\begin{tabular}{lcccc}
\hline & Global & $\bar{K}$ & $\mathrm{Mg}$ & $\mathrm{K} / \mathrm{Mg}$ \\
\hline LVEDP (\% of control) & & & & \\
$\quad$ Mature & $174.3 \pm 16.8$ & $124.3 \pm 22.7$ & $104.8 \pm 9.2 \dagger$ & $115.2 \pm 10.7^{*}$ \\
$\quad$ Aged & $260.0 \pm 10.4 \S$ & $161.5 \pm 17.9 \ddagger$ & $182.8 \pm 8.6 \ddagger \S$ & $139.1 \pm 11.9 \dagger$ \\
LVPDP (\% of control) & $71.1 \pm 4.5$ & & & \\
$\quad$ Mature & $57.1 \pm 5.2 \ddagger$ & $74.4 \pm 4.3^{*}$ & $89.0 \pm 4.0 \dagger$ & $95.4 \pm 2.3 \dagger$ \\
$\quad$ Aged & & $74.3 \pm 8.9$ & $67.8 \pm 4.5 \S$ & $78.8 \pm 4.7^{*} \S$ \\
\hline
\end{tabular}

LVEDP and LVPDP are expressed in millimeters of mercury. All results are shown as mean \pm standard deviation for $n=6$ for each group. Global, Hearts subjected to normothermic global ischemia without cadioplegic protection; $K$, hearts subjected to normothermic global ischemia with $20 \mathrm{mmol} / \mathrm{L} \mathrm{KCl}$ cardioplegia. $M g$, hearts subjected to normothermic global ischemia with $20 \mathrm{mmol} / \mathrm{L} \mathrm{MgSO}_{4}$ cardioplegia; $K / M g$, hearts subjected to normothermic global ischemia with both $\mathrm{KCl}$ and $\mathrm{MgSO}_{4}$ cardioplegia. Control values were obtained after 30 minutes of equilibrium.

$* p<0.05$ versus global.

$\dagger p<0.01$ versus global.

tp $<0.05$ versus mature.

$\S p<0.01$ versus mature.

after 30 minutes of reperfusion in mature and aged hearts, is shown in Table II. In the mature heart, LVPDP was significantly lower than the control value in hearts subjected to the global protocol $(p<$ 0.001 , Table II). With the $\mathrm{K}, \mathrm{Mg}$, and $\mathrm{K} / \mathrm{Mg}$ protocols, this decrease was significantly ameliorated ( $p<$ 0.01 vs global protocol).

In the aged heart, LVPDP before ischemia was not significantly different from that found in the mature heart. After 30 minutes of reperfusion, LVPDP in hearts subjected to the global protocol was significantly lower $(p<0.001)$ than LVPDP of aged control hearts and significantly lower $(p<$ 0.05 ) than that found in the mature heart. This indicates that in the aged heart the effects of global ischemia on LVPDP were more pronounced than in mature hearts. LVPDP in the aged heart was significantly increased with $\mathrm{K} / \mathrm{Mg}$ cardioplegia $(p<0.05$ vs global protocol), but not with $\mathrm{K}$ or $\mathrm{Mg}$ cardioplegia (Table II).

The effect of cardioplegia on dry weight/wet weight ratios in the mature and aged heart. No significant differences in dry weight/wet weight ratios were found between mature and aged hearts with any cardioplegic protocol (results not shown).

The effect of nifedipine, ryanodine, and dimethyltiourea on $\left[\mathrm{Ca}^{2+}\right]_{\mathrm{i}}$ accumulation during global ischemia. To elucidate the mechanisms of $\left[\mathrm{Ca}^{2+}\right]_{\mathrm{i}}$ accumulation during 30 minutes of normothermic global ischemia, we performed a parallel study using specific calcium channel inhibitors. The effect of the sarcolemmal voltage-gated calcium channel inhibitor nifedipine, the sarcoplasmic reticulum calciumrelease channel inhibitor ryanodine, and the sodium/ calcium exchange inhibitor dimethylthiourea on
$\left[\mathrm{Ca}^{2+}\right]_{\mathrm{i}}$ accumulation during 30 minutes of global ischemia is shown in Fig. 2. No difference in $\left[\mathrm{Ca}^{2+}\right]_{i}$ accumulation during 30 minutes of global ischemia was observed between hearts subjected to the global protocol and hearts treated with dimethyltiourea. Hearts treated with nifedipine or ryanodine had a gradual increase in $\left[\mathrm{Ca}^{2+}\right]_{\mathrm{i}}$ during ischemia, but at 30 minutes of ischemia $\left[\mathrm{Ca}^{2+}\right]_{\mathrm{i}}$ was significantly lower than in hearts subjected to the global protocol $(294.0 \pm 31.3 \mathrm{nmol} / \mathrm{L}$ and $318.7 \pm 38.1 \mathrm{nmol} / \mathrm{L}$, respectively, vs global protocol, $422.9 \pm 16.9 \mathrm{nmol} / \mathrm{L}$; $p<0.01$ ). Hearts treated with nifedipine in combination with ryanodine had a gradual increase in $\left[\mathrm{Ca}^{2+}\right]_{\mathrm{i}}$ during 30 minutes of global ischemia, but the value was significantly lower than in hearts subjected to the global protocol $(273.0 \pm 44.17 \mathrm{nmol} / \mathrm{L} ; p<$ 0.01 ).

The effect of potassium cardioplegia with nifedipine and ryanodine on $\left[\mathrm{Ca}^{2+}\right]_{i}$ accumulation during global ischemia. To investigate the mechanism of action of magnesium in magnesium-supplemented potassium cardioplegia $(\mathrm{K} / \mathrm{Mg}$ protocol), we treated hearts with nifedipine, ryanodine, or nifedipine/ryanodine, plus and potassium cardioplegia, and measured $\left[\mathrm{Ca}^{2+}\right]_{\mathrm{i}}$ during 30 minutes of normothermic global ischemia. Results shown in Fig. 3 indicate that in hearts subjected to potassium arrest after nifedipine treatment and after ryanodine treatment, $\left[\mathrm{Ca}^{2+}\right]_{\mathrm{i}}$ gradually increased during normothermic global ischemia. At 30 minutes of normothermic global ischemia $\left[\mathrm{Ca}^{2+}\right]_{\mathrm{i}}$ was $273.5 \pm 51.6$ $\mathrm{nmol} / \mathrm{L}$ and $265.1 \pm 43.2 \mathrm{nmol} / \mathrm{L}$ for nifedipine treatment and ryanodine treatment, respectively. No significant difference between nifedipine treatment, ryanodine treatment, and potassium cardioplegia $(\mathrm{K}$ 


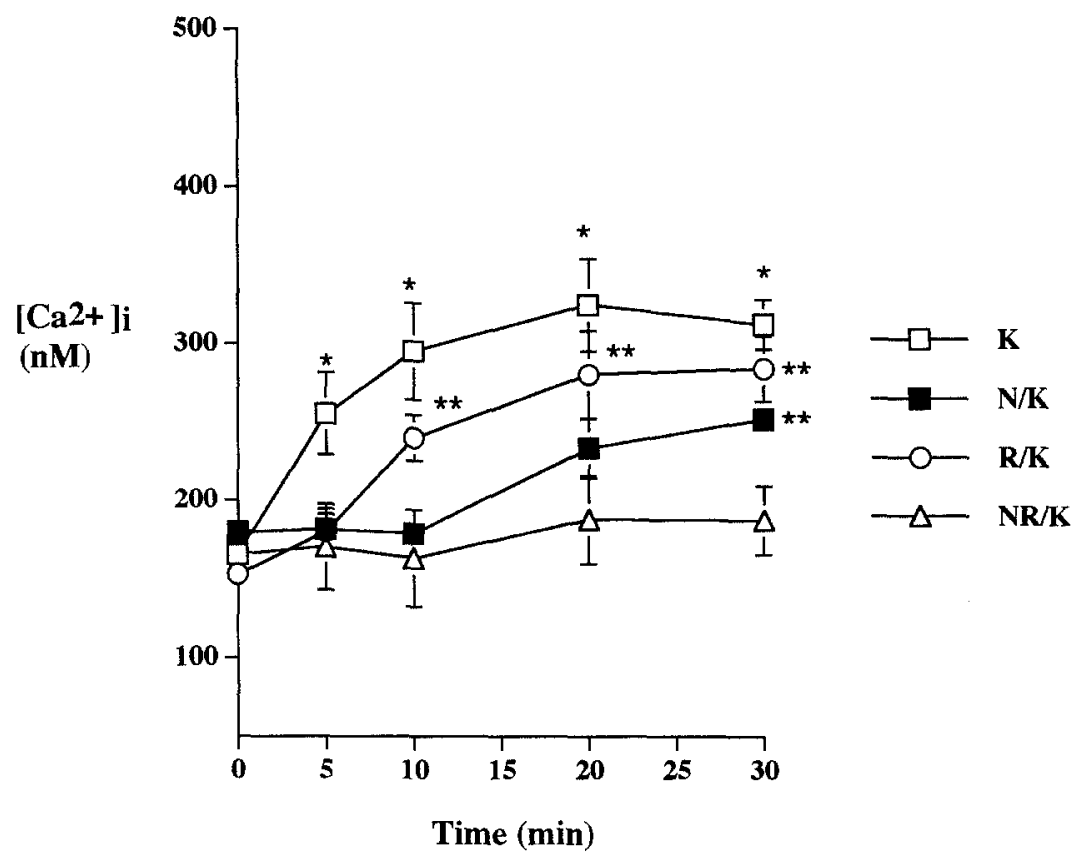

Fig. 3. The effect of potassium cardioplegia $(K)$ with nifedipine $(N / K)$, ryanodine $(R / K)$, and nifedipine plus ryanodine $(N R / K)$ on cytosolic calcium accumulation during 30 minutes of normothermic global ischemia. Control values, after 30 minutes equilibrium, are shown at time $=0$ minutes. Results shown are mean \pm standard deviation for $n=6$ for each group. Differences between groups were determined by two-factor analysis of variance and the Tukey-Kramer test. Results indicate significant differences between $\mathrm{K}$ and $\mathrm{N} / \mathrm{K}$ and $\mathrm{NR} / \mathrm{K}\left({ }^{*} p<0.05\right)$ and between $\mathrm{R} / \mathrm{K}$ and $\mathrm{NR} / \mathrm{K}\left({ }^{* *} p<0.001\right)$.

protocol) was observed. A combination of nifedipine and ryanodine plus potassium cardioplegia maintained $\left[\mathrm{Ca}^{2+}\right]_{\mathrm{i}}$ essentially at control (preischemia) levels during 30 minutes of normothermic global ischemia $(197.0 \pm 19.7 \mathrm{nmol} / \mathrm{L}$ at 30 minutes $)$ and significantly decreased $\left[\mathrm{Ca}^{2+}\right]_{\mathrm{i}}$ accumulation as compared with potassium cardioplegia alone $(\mathrm{K}$ protocol) $(p<0.001)$. No differences in $\left[\mathrm{Ca}^{2+}\right]_{\mathrm{i}}$ accumulation during 30 minutes of normothermic global ischemia were observed between hearts treated with a combination of nifedipine and ryanodine plus potassium cardioplegia and those treated with $\mathrm{K} / \mathrm{Mg}$ cardioplegia (Fig. 1, $A$ and Fig. 3).

Transmission electron microscopy. To investigate whether the differences observed in $\left[\mathrm{Ca}^{2+}\right]_{\mathrm{i}}$ accumulation, during 30 minutes of normothermic global ischemia, were the result of ultrastructural differences in the mature and aged myocardium, we performed transmission electron microscopy (Fig. 4). Results indicate that no sarcolemmal damage could be detected at 30 minutes of normothermic global ischemia, nor was there any observable damage to T-tubules, the myofilaments, or the nuclear membrane in either the mature or aged myocardium.

\section{Discussion}

Partial control of $\left[\mathrm{Ca}^{2+}{ }_{i}\right]$ accumulation from surgically induced myocardial ischemia during cardiac operations is achieved through the use of cardioplegic solutions. ${ }^{6,9,11,12}$ Most cardioplegic solutions use a high potassium concentration to arrest the heart, increase the available intraoperative time, and reduce postoperative mortality. ${ }^{11}$ Potassiuminduced arrest maintains the heart in a depolarized state, significantly decreasing the energy demand of the myocardium. However, basal metabolic energy requirements are sustained and still constitute a significant energy expenditure. ${ }^{5}$ Sternbergh and associates $^{5}$ demonstrated that in hearts arrested with potassium $(20 \mathrm{mmol} / \mathrm{L})$, myocardial oxygen consumption was significantly higher than that of polarized (tetrodotoxin-induced) hearts. They concluded that $\left[\mathrm{Ca}^{2+}\right]_{\mathrm{i}}$ accumulation increased energy requirements in the potassium-arrested heart. They also speculated that this higher $\left[\mathrm{Ca}^{2+}\right]_{\mathrm{i}}$ accumulation might 


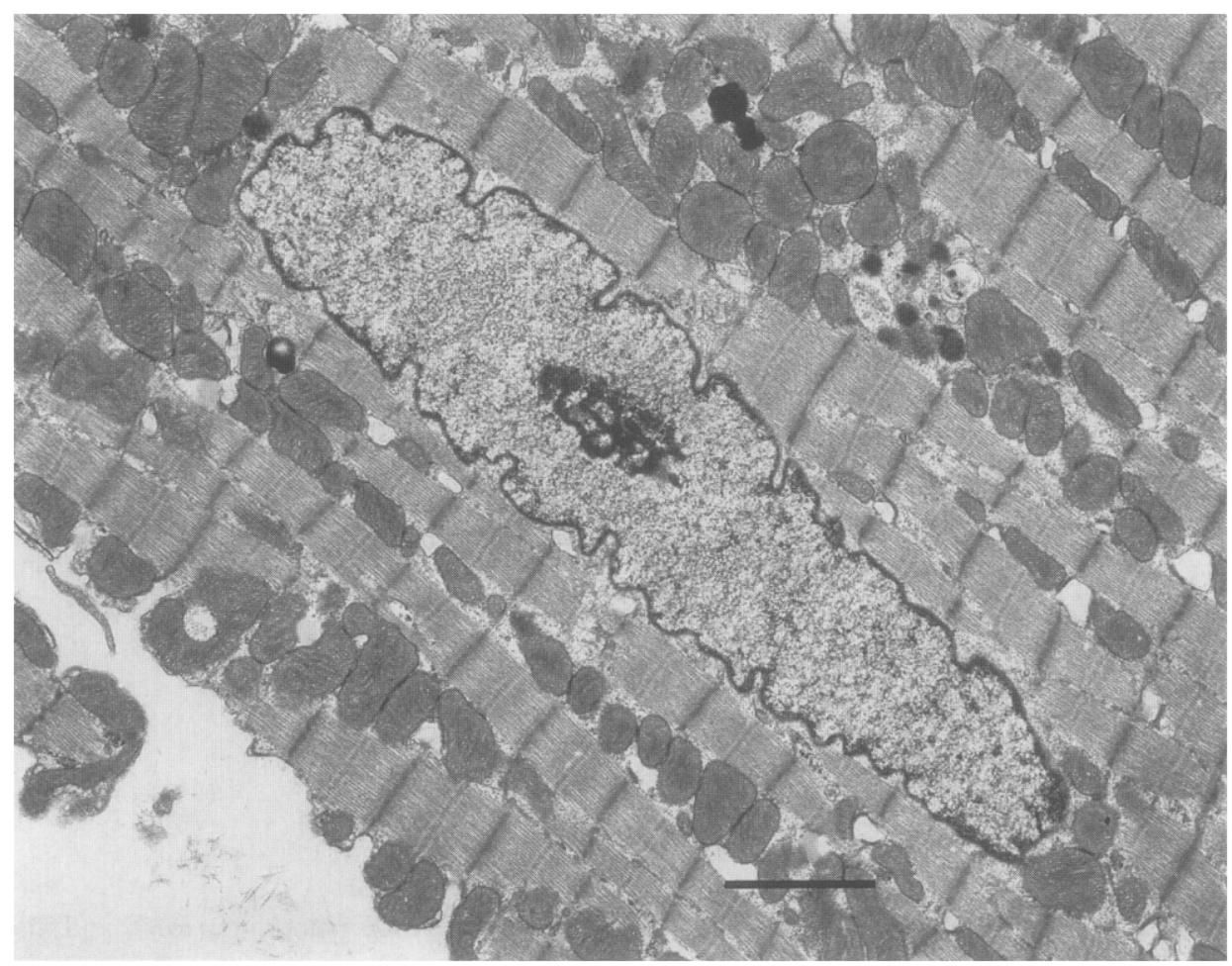

Fig. 4. Electron micrograph of aged rabbit myocardium after 30 minutes of normothermic ischemia, showing intact sarcolemma, T-tubules, nuclear membrane, and myofilaments. Magnification $\times 10,000$. $B a r=2 \mu \mathrm{m}$.

be mediated by the voltage-dependent sodium/calcium exchanger.

Alternatives to potassium cardioplegia have been suggested to allow for enhanced functional recovery of the myocardium after ischemia/reperfusion. Hearse, Garlick, and Humphrey ${ }^{6}$ reported that magnesium, when included in potassium cardioplegic solution (St. Thomas' Hospital), was beneficial to coronary flow and aided in the reduction of myocardial enzymatic leakage in the ischemic and reperfused heart. Recently, Steenbergen and colleagues ${ }^{3}$ have examined the relationship between adenosine triphosphate depletion, $\left[\mathrm{Ca}^{2+}\right]_{i}$ concentration, and lethal myocardial ischemic injury in the perfused rat heart using nuclear magnetic resonance. They reported that high-magnesium $(16 \mathrm{mmol} / \mathrm{L})$ arrest delayed $\left[\mathrm{Ca}^{2+}\right]_{\mathrm{i}}$ accumulation and adenosine triphosphate depletion longer than high-potassium $(30 \mathrm{mmol} / \mathrm{L})$ arrest during normothermic ischemia in the mature rat heart.

Engelman and coworkers ${ }^{13}$ have indicated that normothermic cardioplegic arrest was associated with lower $\left[\mathrm{Ca}^{2+}\right]_{\mathrm{i}}$ transients than hypothermic cardioplegic arrest. Even though this beneficial temper- ature was maintained in the present experiments, we have found a significant difference in $\left[\mathrm{Ca}^{2+}\right]_{\mathrm{i}}$ accumulation during both ischemia and reperfusion between mature and aged hearts. Magnesium and magnesium-supplemented potassium cardioplegia ( $\mathrm{Mg}$ and $\mathrm{K} / \mathrm{Mg}$ protocols) significantly reduced $\left[\mathrm{Ca}^{2+}\right]_{\mathrm{i}}$ accumulation during 30 minutes of normothermic global ischemia as compared with global ischemia without cardioplegic protection in both the mature and the aged heart. It is important to note that the effects of cardioplegia in ameliorating $\left[\mathrm{Ca}^{2+}\right]_{\mathrm{i}}$ accumulation during global ischemia were modulated by age, with the aged heart accumulating significantly more $\left[\mathrm{Ca}^{2+}\right]_{i}$ during global ischemia with magnesium and magnesium-supplemented potassium cardioplegia than the mature hearts.

It is possible that the differences in $\left[\mathrm{Ca}^{2+}\right]_{\mathrm{i}}$ accumulation observed may have reflected age-related alterations to ischemia in sarcolemmal or intracellular membrane integrity. Previous reports have indicated that 20 minutes of ischemia resulted in necrosis of only a few severely ischemic cells, whereas 40 minutes of ischemia resulted in the death of about three quarters of the cells. ${ }^{14}$ Irrevers- 
ible cellular injury is evident in almost all myocytes after 50 to 60 minutes of ischemia. ${ }^{14}$ In our investigations, examination of myocardial cells with transmission electron microscopy revealed that no differences in sarcolemmal membrane, T-tube, nuclear membrane, or sarcoplasmic reticulum membrane integrity were evident between mature and aged hearts after 30 minutes of normothermic global ischemia. These results suggest that the use of 30 minutes of normothermic global ischemia in these experiments did not detectably alter the myocardial cellular structure of either the mature or aged heart such that $\left[\mathrm{Ca}^{2+}\right]_{\mathrm{i}}$ accumulation would be enhanced.

The mechanism(s) by which high-magnesium cardioplegia ameliorates $\left[\mathrm{Ca}^{2+}\right]_{\mathrm{i}}$ accumulation during normothermic global ischemia in the myocardium is not clear. High magnesium concentration has been suggested to inhibit calcium entry into cell by displacing calcium from its binding sites in the sarcolemmal membrane and by hyperpolarization of the sarcolemmal membrane. ${ }^{15,16}$ It has been suggested that elevated extracellular magnesium, when supplied before global ischemia, acts by raising cytosolic magnesium concentrations, thereby reducing the release of calcium from sarcoplasmic reticulum. ${ }^{17}$ The replenishment of magnesium in ischemic hearts may also diminish the depletion of adenosine triphosphate stores, thereby protecting the phosphorylation function of mitochondria during and after reperfusion. ${ }^{9}$

Ziegelstein and associates ${ }^{10}$ reported that $\left[\mathrm{Ca}^{2+}\right]_{\mathrm{i}}$ accumulation during hypoxia was significantly blunted by dimethyltiourea, which inhibits the sarcolemmal sodium/calcium exchanger. (Dimethylthiourea does not interfere with cellular fluorescence measurements. ${ }^{18}$ ) Our results indicate that in the rabbit heart the sodium/calcium exchanger does not play a significant role in $\left[\mathrm{Ca}^{2+}\right]_{\mathrm{i}}$ accumulation during 30 minutes of normothermic global ischemia. One explanation for this difference may be the reversed potentials of the rat and rabbit myocardium sodium/calcium exchangers. ${ }^{19}$

Our results show that nifedipine, a slow inward (1-type) calcium channel antagonist, reduces $\left[\mathrm{Ca}^{2+}\right]_{\mathrm{i}}$ accumulation during 30 minutes of normothermic global ischemia to $40 \%$ of $\left[\mathrm{Ca}^{2+}\right]_{\mathrm{i}}$ accumulation in global ischemia. These data indicate that $\left[\mathrm{Ca}^{2+}\right]_{\mathrm{i}}$ accumulation during 30 minutes of normothermic global ischemia occurs partially through the slow inward calcium channel, in agreement with Liu and associates, ${ }^{20}$ who have shown that dihydropyridine calcium channel antagonists reduce $\left[\mathrm{Ca}^{2+}\right]_{\mathrm{i}}$ tran- sients and myocardial $\left[\mathrm{Ca}^{2+}\right]_{\mathrm{i}}$ contents during ischemia. When nifedipine was used in combination with potassium cardioplegia, no further reduction in $\left[\mathrm{Ca}^{2+}\right]_{\mathrm{i}}$ accumulation at 30 minutes of normothermic global ischemia was observed. These results are in agreement with those of Powell, Tatham, and Twist, ${ }^{21}$ who showed that sarcolemmal calcium channels were activated when myocardial $\left[\mathrm{Ca}^{2+}\right]_{i}$ was increased during hyperkalemic depolarization.

The use of ryanodine, a sarcoplasmic reticulum calcium-release channel antagonist when administered at high concentrations, was found to reduce $\left[\mathrm{Ca}^{2+}\right]_{\mathrm{i}}$ accumulation during 30 minutes of normothermic global ischemia to $70 \%$ of $\left[\mathrm{Ca}^{2+}\right]_{\mathrm{i}}$ accumulation in our global protocol. These results indicate that $\left[\mathrm{Ca}^{2+}\right]_{i}$ accumulation during 30 minutes of normothermic global ischemia also occurs partially by the sarcoplasmic reticulum calcium-release channels. The $30 \%$ reduction in $\left[\mathrm{Ca}^{2+}\right]_{i}$ accumulation agrees with the results of Bers and Chrestensen, ${ }^{22}$ who have shown that rabbit ventricular muscle contraction is only modestly depressed by ryanodine (approximately $30 \%$ ). These authors suggested that in the rabbit ventricle the sarcoplasmic reticulum calcium-release channel played a less important role in $\left[\mathrm{Ca}^{2+}\right]_{\mathrm{i}}$ accumulation than in the rat heart. ${ }^{22}$

When nifedipine and ryanodine were used in combination, $\left[\mathrm{Ca}^{2+}\right]_{i}$ accumulation during $30 \mathrm{~min}$ utes of normothermic global ischemia was significantly reduced as compared with results with our global protocol, but no difference in $\left[\mathrm{Ca}^{2+}\right]_{\mathrm{i}}$ accumulation was observed when compared with potassium $\left(\mathrm{K}^{+}\right)$cardioplegia. However, when potassium $\left(\mathrm{K}^{+}\right)$cardioplegia was supplemented with both nifedipine and ryanodine, $\left[\mathrm{Ca}^{2+}\right]_{\mathrm{i}}$ accumulation was significantly reduced during 30 minutes of normothermic global ischemia as compared with potassium $\left(\mathrm{K}^{+}\right)$cardioplegia alone. There was no difference between magnesium-supplemented potassium cardioplegia ( $\mathrm{K} / \mathrm{Mg}$ protocol) and nifedipine and ryanodine used in combination with potassium $\left(\mathrm{K}^{+}\right)$ cardioplegia in reducing $\left[\mathrm{Ca}^{2+}\right]_{\mathrm{i}}$ accumulation during 30 minutes of normothermic global ischemia.

These results suggest that the action of magnesium in magnesium-supplemented potassium cardioplegia acts in a similar manner to the combined use of nifedipine and ryanodine in potassium cardioplegia, by inhibiting $\left[\mathrm{Ca}^{2+}\right]_{i}$ accumulation from 1-type calcium channels and the sarcolemmal calcium channels. The action of magnesium would appear to inhibit calcium entry possibly through the displacement of calcium from its binding sites on the 
sarcolemmal calcium channels ${ }^{15,23}$ and the reduction of sarcoplasmic reticulum loading before or during ischemia. ${ }^{3}$

\section{Conclusion}

The use of magnesium-supplemented potassium cardioplegia allows for modulation of cytosolic calcium accumulation during normothermic global ischemia in both the mature and aged heart. The modulating action of magnesium-supplemented potassium cardioplegia on cytosolic calcium accumulation during normothermic global ischemia would appear to inhibit 1-type calcium channel and the sarcolemmal calcium channels. The use of magnesium-supplemented potassium cardioplegia may reduce the morbidity and mortality of cardiac operations in the aged patient.

\section{REFERENCES}

1. Lakatta E. Cardiovascular regulatory mechanisms in advanced age. Physiol Rev 1993;73:413-67.

2. Ataka K, Chen DP, Levitsky S, Jimenez E, Feinberg H. Effect of aging on intracellular $\mathrm{Ca}^{2+}, \mathrm{pH}_{\mathrm{i}}$, and contractility during ischemia and reperfusion. Circulation 1992;86(Suppl):II371-6.

3. Steenbergen C, Murphy E, Watts J, London R. Correlation between cytocolic free calcium, contracture, ATP, and irreversible ischemic injury in perfused rat heart. Circ Res 1990;66:135-46.

4. Wright R, Levitsky S, Rao K, Holland C, Feinberg $H$. Potassium cardioplegia. Arch Surg 1978;113:976-80.

5. Sternbergh WC, Brunsting LA, Abd-Elfattah AS, Wechsler AS. Basal metabolic energy requirements of polarized and depolarized arrest in rat heart. Am J Physiol 1989;256:H84651.

6. Hearse DJ, Garlick PB, Humphrey SM. Ischemic contracture of the myocardium: mechanism and prevention. Am J Cardiol 1977;39:986-93.

7. Hearse D, Stewart D, Braimbridge M. Myocardial protection during ischemic cardiac arrest: the importance of magnesium in cardioplegic infusates. J Thorac Cardiovase Surg 1978;75: $877-85$.

8. Chen DP, Jimenez E, Ataka K, Levitsky S, Feinberg H. Fura 2 determination of $\left[\mathrm{Ca}^{2+}\right]_{\mathrm{i}}$ in isolated perfused heart using $\mathrm{R}$ wave-gated electromechanical shutters. J Appl Physiol 1994; 76:1394-9.

9. Tsukube T, McCully JD, Faulk E, Federman M, LoCicero J,
Krukenkamp IB, et al. Magnesium cardioplegia reduces cytosolic and nuclear calcium and DNA fragmentation in the senescent myocardium. Ann Thorac Surg 1994;58:1005-11.

10. Ziegelstein R, Zweier J, Mellits E, et al. Dimethylthiourea, an oxygen radical scavenger, protects isolated cardiac myocytes from hypoxic injury by inhibition of $\mathrm{Na}^{+}-\mathrm{Ca}^{2+}$ exchange and not by its antioxidant effects. Circ Res 1992;70:804-11.

11. Wright R, Levitsky S, Rao K, Holland C, Feinberg H. Potassium cardioplegia. Arch Surg 1978;113:976-80.

12. Burkhoff D, Kalil-Filho R, Gerstenblith G. Oxygen consumption is less in rat hearts arrested by low calcium than by high potassium at fixed flow. Am J Physiol 1990;259:H1142-7.

13. Engelman RM, Liu XK, Rousou JA, Flack JE, Deaton DW, Das DK. Intracellular $\mathrm{Ca}^{2+}$ transients during open heart surgery: hypothermic versus normothermic cardioplegic arrest. Ann N Y Acad Sci 1994;723:229-38.

14. Jennings RB, Hawkins $H$. Ultrastructural changes of acute myocardial ischemia. In: Wildenthal K, editor. Degenerative processes in heart and skeletal muscle. Amsterdam: Elsevier/ North Holland, 1980:295-346.

15. Lansman JB, Hess P, Tsien RW. Blockade of current through single calcium channels by $\mathrm{Cd}^{2+}, \mathrm{Mg}^{2+}$, and $\mathrm{Ca}^{2+}$ : voltage and concentration dependence of calcium entry into the pore. J Gen Physiol 1986;88:321-47.

16. Matsuda $\mathrm{H}$. Magnesium gating of the inwardly rectifying $\mathrm{K}^{+}$ channel. Ann Rev Physiol 1991;53:289-98.

17. Reimer K, Jennings R. Myocardial ischemia, hypoxia, and infarction. In: Fozzard H, editor. The heart and cardiovascuIar system. 2nd ed. New York: Raven Press, 1992:1875-973.

18. Haigney MC, Miyata H, Lakatta EG, Stem MD, Silverman HS. Dependence of hypoxic cellular calcium loading on $\mathrm{Na}^{+}-\mathrm{Ca}^{2+}$ exchange. Circ Res 1992;71:547-57.

19. Shattock MJ, Bers DM. Rat vs. rabbit ventricle: Ca flux and intracellular $\mathrm{Na}$ assessed by ion-selective microelectrodes. Am J Physiol 1989;256:C813-22.

20. Liu X, Engelman RM, Wei Z, et al. Attenuation of myocardial reperfusion injury by reducing intracellular calcium overloading with dihydropyridines. Biochem Pharmacol 1993; 45:1333-41.

21. Powell T, Tatham P, Twist V. Cytoplasmic free calcium measured by Quin 2 fluorescence in isolated ventricular myocytes at rest and during potassium depolarization. Biochem Biophys Res Commun 1984;122:1012-20.

22. Bers DM, Chrestensen DM. Functional interconversion of rest decay and ryanodine effects in rabbit and rat ventricle depends on $\mathrm{Na} / \mathrm{Ca}$ exchange. J Mol Cell Cardiol 1990;22:71523.

23. Agus Z, Morad M. Modulation of cardiac ion channels by magnesium. Ann Rev Physiol 1991;53:299-307. 